\title{
Leiomioma uretral durante a gravidez: relato de caso
}

\section{Urethral leiomyoma during pregnancy: a case report}

\author{
Arlon Breno Figueiredo Nunes da Silveira'; Cassio luis Zanettini Riccetto²; Viviane Herrmann33; \\ Paulo César Rodrigues Palma, TCBC-SP4; Juliane de Fátima Agostini Tiecher ${ }^{5}$
}

\section{INTRODUÇÃO}

$\mathrm{O}$ leiomioma uretral é um tumor raro, seu local de implantação mais comum nos órgãos femininos é o útero. É considerado um tumor de comportamento benigno com origem no músculo liso'.

Alguns pesquisadores acreditam que o desenvolvimento dos miomas tem relação com hormônios ovarianos ${ }^{2}$. Relatos têm mencionado a progressão do mioma durante a gravidez, regressão após o parto ou a coexistência do útero miomatoso, o que confirma a relação de dependência hormonal ${ }^{3}$.

O leiomioma uretral pode se apresentar como uma massa na parede vaginal anterior ou uma protrusão originária do meato uretral. Acomete mais mulheres que homens ${ }^{1}$. Pode ocorrer em qualquer segmento uretral, o local mais frequentemente acometido é a porção proximal.

O diagnóstico diferencial deve ser feito com prolapsos de parede vaginal anterior, divertículo uretral, cisto do ducto de Gartner, cisto parauretral congênito, prolapso uterino e tumores sólidos como linfoma, carcinoma e sarcoma'.

Tendo em vista a raridade da doença, os autores relatam um caso de leiomioma uretral durante a gravidez, enfatizando a conduta adotada antes e após o parto.

\section{RELATO DO CASO}

DAS, sexo feminino, 22 anos de idade, branca, gestação de 33 semanas, com nódulo vaginal há sete meses. Refere que há um ano detectou um pequeno nódulo na vagina, oligossintomático. Após o inicio da gravidez, o nódulo cresceu rapidamente passando a ser visível, desencadeando incomodo ao sentar e deambular. Queixava-se de jato urinário divergente e sangramento por escoriações.

Ao exame, o nódulo localizava-se no introito vaginal, protruso, recoberto de mucosa, com vascularização aumentada, sua base encontrava-se em contato com a borda superior do meato uretral externo, de consistência fibroelástica. A massa não obstruía totalmente o meato uretral e, à palpação da uretra, não foi identificada extensão da massa além deste ponto. A avaliação obstétrica não apresentava alterações significativas (Figura 1).

Inicialmente optou-se por realizar biópsia. Foram retirados dois fragmentos localizados na base e no ápice da lesão. A análise histológica demonstrou segmento de tecido muscular liso, entrecruzado, sem atipias, associado à uretrite crônica inespecífica, correspondente a leiomioma.

A gestação foi interrompida com 38 semanas por parto cesárea, procedimento realizado sem intercorrências no intraoperatório. No período puerperal a lesão assumiu discreta regressão em suas dimensões e apresentou sangramentos menos frequentes.

Após 30 dias do parto, foi feita a retirada da massa uretral. O procedimento consistiu em exérese da lesão na borda superior do meato uretral com sutura em pontos separados de absorção tardia (Figura 2). A paciente teve evolução pós-operatória satisfatória. O histopatológico da massa retirada revelou neoplasia fusocelular compatível com leiomioma, associado a processo inflamatório com tecido de granulação.

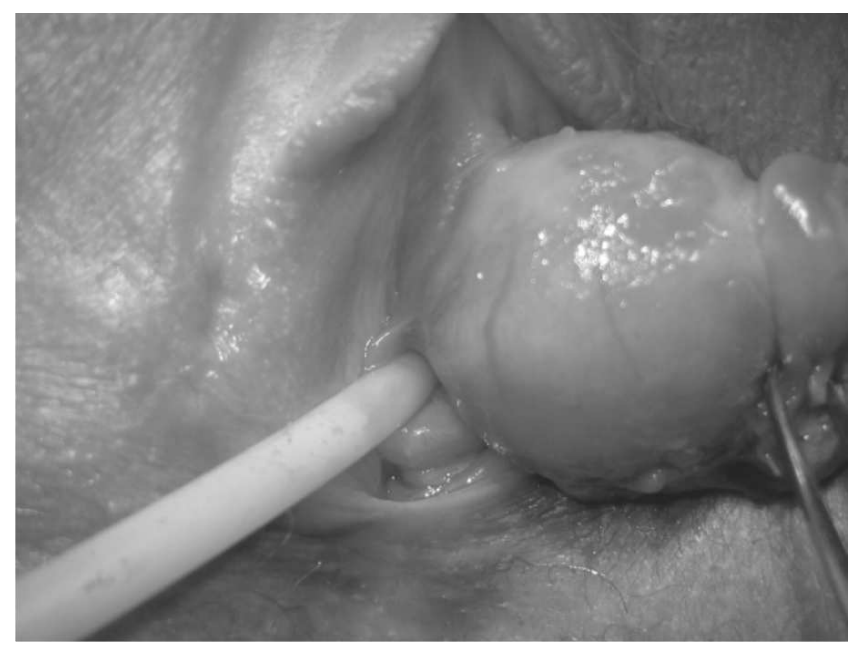

Figura 1 - Nódulo localizado no introito vaginal com sua base em contato com a borda superior do meato uretral externo.

Trabalho realizado na Disciplina de Uroginecologia, Faculdade de Ciências Médicas, Universidade Estadual de Campinas, SP. (UNICAMP). 1. Mestrando em Cirurgia da Universidade Estadual de Campinas - UNICAMP-LASP-BR; 2. Prof. Dr. Disciplina de Urologia da UNICAMP; 3 . Prof. Dra. Disciplina de Ginecologia da UNICAMP; 4. Prof. Dr. Titular da Disciplina de Uroginecologia da UNICAMP; 5. Mestranda em Cirurgia da Universidade Estadual de Campinas - UNICAMP. 


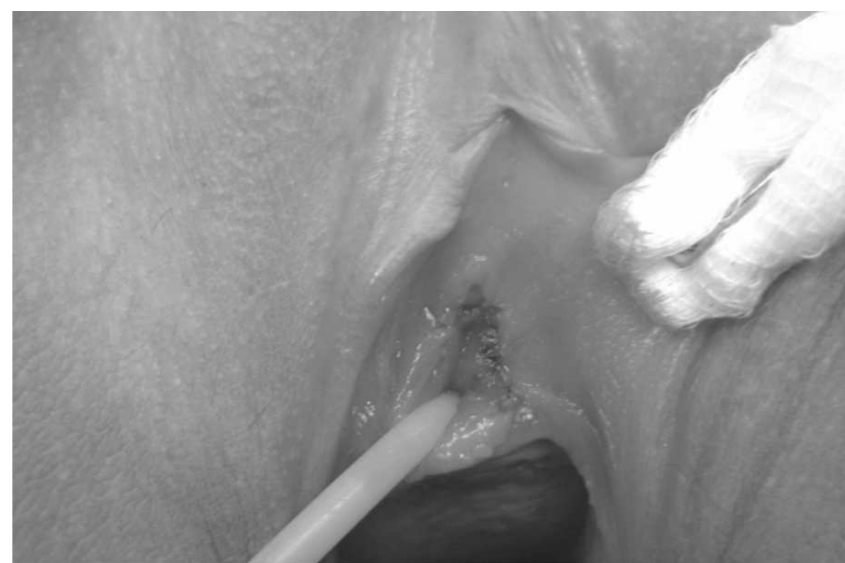

Figura 2 - $\quad$ Aspecto final após a exérese do nódulo miomatoso.

\section{DISCUSSÃO}

O surgimento do leiomioma associado à gravidez assume características peculiares devido às alterações anatômicas do sistema urinário e ao estado hormonal gravídico. Os sintomas mais comumente apresentados incluem infecção do trato urinário (64,3\%), presença de massa tumoral $(50 \%)$, dispareunia $(28,5 \%)^{4}$ e obstrução urinária, mais raramente. A obstrução e a infecção do trato urinário não ficaram comprovadas clínica e laboratorialmente, sendo os demais sintomas da paciente compatíveis com os dados da literatura apresentados.

A sensibilidade dos leiomiomas ao estrógeno é bem conhecida e a presença dos receptores estrogênicos sugere essa responsividade ao hormônio ${ }^{5}$. Em nosso caso houve um aumento das dimensões do leiomioma após inicio da gravidez, sugerindo também dependência hormonal do tecido miomatoso.

A excisão local completa ou transuretral é o tratamento recomendado para o leiomioma uretral ${ }^{1}$. Na revisão literária, percebe-se que todos os casos de leiomioma uretral tiveram como tratamento a excisão cirúrgica. Quando o leiomioma é contíguo com a uretra proximal ou com o colo vesical, a cirurgia pode causar complicações como estenose uretral, fístula uretrovaginal e incontinência urinária'.

A terapia hormonal pode ser efetiva dependendo da situação. Considerando que leiomioma uretral tem características semelhantes ao mioma uterino, pode se esperar por uma regressão espontânea ao atingir o período pós-menopausa ${ }^{3}$. Em nosso caso, a paciente não estava próxima da menopausa e a massa estava causando sintomas importantes, optando-se então pela retirada da lesão.

Na revisão literária, não existem casos descritos de degeneração maligna. Sendo assim, não é necessário o acompanhamento da paciente por longo tempo, tendo em vista a ausência de relatos que confiram potencial de malignidade à lesão.

\title{
A $B$ S T T R A C T
}

\begin{abstract}
The authors report a case of urethral leiomyoma diagnosed during pregnancy, which was conservatively treated up to the 38th week, when the pregnancy was interrupted. Thirty days after delivery, exeresis of the lesion was performed from the upper border of the urethral meatus and sutured with interrupted delayed-absorbable suture. The patient evolved favorably and presented no lesion recurrence during three months of follow up.
\end{abstract}

Key words: Neoplasms. Urethral neoplasms. Leiomyoma. Urethra. Pregnancy.

\section{REFERÊNCIAS}

1. Goto K, Orisaka S, Kurokawa T, Miyazaki M, Kotsuji F. Leiomyoma of the female urethra: urodynamic changes after surgical intervention. Int Urogynecol J Pelvic Floor Dysfunct. 2005;16(2):1624.

2. Ichimura T, Kawamura N, Ito F, Shibata S, Minakuchi K, Tsujimura $A$, et al. Correlation between the growth of uterine leiomyomata and estrogen and progesterone receptor content in needle biopsy specimens. Fertil Steril. 1998;70(5):967-71.

3. Kato T, Kobayashi T, Ikeda R, Nakamura T, Akakura K, Hikage T, et al. Urethral leiomyoma expressing estrogen receptors. Int J Urol. 2004;11(7):573-5.

4. Mooppan MM, Kim H, Wax SH. Leiomyoma of the female urethra. J Urol. 1979;121(3):371-2.
5. Tamaya T, Fujimoto J, Okada H. Comparison of cellular levels of steroid receptors in uterine leiomyoma and myometrium. Acta Obstet Gynecol Scand. 1985;64(4):307-9.

Recebido em 20/04/2007

Aceito para publicação em 25/05/2007

Conflito de interesse: nenhum

Fonte de financiamento: nenhum

\section{Como citar este artigo:}

Silveira ABFN, Riccetto CLZ, Herrmann V, Palma PCR, Tiecher JFA. Leiomioma uretral durante a gravidez: relato de caso. Rev Col Bras Cir. [periódico na Internet] 2012; 39(6). Disponível em URL: http:// www.scielo.br/rcbc

\section{Endereço para correspondência:}

Paulo César Rodrigues Palma

E-mail:ppalma@uol.com.br 